\title{
Issues and Experiences in Logistics Collaboration
}

\author{
Nadia Lehoux ${ }^{1}$, Jean-François Audy ${ }^{1}$, Sophie D`Amours ${ }^{1}$, \\ and Mikael Rönnqvist ${ }^{2}$ \\ ${ }^{1}$ FORAC,CIRRELT, Université Laval, Québec, Canada \\ ${ }^{2}$ Norwegian School of Economics and Business Administration, Bergen, Norway \\ Nadia.Lehoux@cirrelt.ca, Jean-Francois.Audyacirrelt.ca, \\ Sophie.Damours@gmc.ulaval.ca, Mikael.Ronnqvist@nhh.no
}

\begin{abstract}
Collaborative logistics is becoming more important in today's industry. This is driven by increased environmental concerns, improved efficiency through collaborative planning supporting resources sharing and new business models implementation. This paper explores collaborative logistics and reports on business applications within the forest products industry in Sweden and Canada. It first describes current opportunities in collaborative planning. It then discusses issues related to building the coalition as well as sharing resources and benefits. Three business cases are described and used to support the discussion around these main issues. Finally, different challenges are detailed, opening new paths for researchers in the field.
\end{abstract}

Keywords: Collaborative logistics, inter-firm collaborations, game theory.

\section{Introduction}

Logistics and transportation are activities that provide many opportunities for collaboration between companies. This collaboration, either through information or resource sharing, aims to reduce the cost of executing the logistics activities, improve service, enhance capacities as well as protect environment and mitigate climate change. Specifically, collaboration occurs when two or more entities form a coalition and exchange or share resources (including information), with the goal of making decisions or realizing activities that will generate benefits that they cannot (or only partially) generate individually. This can range from information exchange, joint planning, joint execution, up to strategic alliance (e.g. co-evolution) (D'Amours et al., 2004). Collaborative logistics may involve different levels of resource and information sharing between two or many entities. It can be driven by a voluntary action or imposed by certain policies. It can also bring together business entities which are competitors, collaborators or supplier/customers. In addition, collaboration is related to some forms of interdependency. Frayret et al. (2004) have reviewed these forms. They are listed and briefly described in Table 1.

In this paper, we will discuss motivations and issues related to building a coalition of business entities aiming for collaborative logistics. We will also describe three case studies and express how, in different types of collaboration scheme, enterprises have addressed challenges related to coalition building and benefit sharing. 
Table 1. Forms of interdependency

\begin{tabular}{ll}
\hline \multicolumn{1}{c}{ Type of relation } & \multicolumn{1}{c}{ Description } \\
\hline 1. Pooled interdependence & $\begin{array}{l}\text { Occurs when each part of a system renders a discrete contribution } \\
\text { to the whole, while each part is supported by the whole }\end{array}$ \\
$\begin{array}{ll}\text { 2. Producer-consumer relationship } \\
\text { or sequential interdependence }\end{array}$ & $\begin{array}{l}\text { Links two manufacturing activities for which the output of one is } \\
\text { the input of the other } \\
\text { 3. Reciprocal relationships }\end{array}$ \\
$\begin{array}{l}\text { Concerns activities whose outputs are the reciprocal inputs of the } \\
\text { other activity } \\
\text { Relates to the intrinsic sophistication of activities that are imbed- } \\
\text { ded }\end{array}$ \\
$\begin{array}{ll}\text { 4. Intensive interdependence } \\
\text { 6. Simultaneity interdependence }\end{array}$ \\
$\begin{array}{ll}\text { Occurs when activities need to be performed, or not, at the same } \\
\text { time, such as for meeting scheduling }\end{array}$ \\
\hline
\end{tabular}

\section{Collaborative Logistics}

Logistics deal with moving and storing products as they flow through the supply chain. Efficient logistics planning and execution can provide competitive advantages to the different entities of the supply chain. Moreover, collaboration in logistics based on information exchanged has been identified as one means of reducing the negative impacts of the bullwhip effect, known as the amplification of demand variation going upstream the supply chain (Lee et al., 1997, Moyaux et al., 2004). The supply chain entities such as carrier, producer, customer and third party logistics collaborate in different ways. In terms of transportation, they try to optimize the traveling time and load capacity usage. They share information to capture the benefit of a denser network, aiming to minimize transportation costs, in particular the backhauling costs (i.e. combining two transport orders to minimize the unloaded distance). The supply chain entities may also collaborate to increase responsiveness and reduce inventory holding costs. In such cases, they share demand and consumption information in a timely manner and use different approaches to synchronize efficiently their activities.

\subsection{Strategic and Operational Collaboration in Logistics}

Enterprises may face large transportation costs and aim to deploy new infrastructures that will provide them with a competitive advantage over others. Such shared infrastructure could be pipelines (e.g. crude oil and gas); terminals (e.g. forestry); warehouses (e.g. retailing) or transportation modes (integrating e.g. train, ship, truck in general transportation organizations). The location and the investment for such infrastructure are considered strategic for the entities involved. Other strategic collaboration relates to defining industry standards. This is the case when entities of a same industry collaborate to define business standards so as to improve the interoperability of their systems (e.g. PapiNet - a standard for information exchange in the forest products industry). Strategic collaboration can also imply a long term business contract and the exchange of demand and capacity information. At the strategic level, it is likely to see entities exchanging a "complete" model of their demand or capacity, permitting the coalition to compute the value of the collaboration and to propose a realistic sharing strategy (Montreuil et al., 1999, Frisk et al., 2006). On the other 
hand, operational collaboration requires low commitment. An example of such collaborations could be a web based platform inviting enterprises to share their transportation needs so as to find joint routes that will reduce their transportation costs. Applications can be found in the Swedish and Finnish forest industry. In Erikson and Rönnqvist (2003), a web-based transportation planning tool is described. Here, a backhauling solution is provided to all transport planners in several regions and companies in order to support manual planning of daily routes.

Collaboration can bring together two or more entities. In all cases, the need for each entity to improve its logistics is a prerequisite for the collaboration. In a manyto-many context, the design of proper collaboration mechanisms is more difficult, mainly because the exchanges are not bilateral as in a supplier-customer type of collaboration. Some entities may enter with a lot to provide and little to gain, while others will benefit greatly with little to offer.

While collaboration usually emerges from a coalition of voluntary entities that share information to improve their logistics, this may also be imposed by one of the leading entities of the supply chain. For example, WalMart move to set RFID systems with all major suppliers was done in order to increase the collaboration but it was imposed on the different entities. Other imposed schemes can be set by public policies. For example, natural resources can be managed by governmental authorities and the allocation rules may impose collaboration between many entities. This is the case in the forestry industry in Canada where the different entities are asked to find harvesting plans which meet the coalition members' needs (Beaudoin et al., 2007).

In a context where a supplier and a customer aim for more efficiency in their logistics, they can evaluate the possibility of exchanging more information and plan jointly their activities. Several responsibilities can also be shifted from one entity to another so the global efficiency of the coalition is improved. For example, under a Vendor Managed Inventory (VMI) agreement, the producer is responsible for managing the inventory of its customer. The customer provides the daily consumption to the producer so it can build a production-distribution plan that meets the fixed service level as well as optimizes the usage of its resources. The VMI approach has contributed positively to enhancing the logistics performance. Danese (2006) reported the benefits gained by the pharmaceutical giant GlaxoSmithKline. Another example of technique frequently implemented by companies is Continuous Replenishment (CR), where the replenishment is structured around a pre-scheduled reservation of capacity. In particular, the collaboration may set a one truck per day delivery to the customer. Then, the customer is responsible for setting the mix of products to be on the truck every day. This approach satisfies the needs of the customer over time and reduces the pressure on the producer. Finally, the Collaborative Planning, Forecasting and Replenishment (CPFR) business model aims to balance demand and production-distribution capacity up-front in order to define a win-win unique plan for both parties. Cederlund et al. (2007) reported reduction of $50 \%$ of transportation costs and $30 \%$ of inventory holding costs at Motorola.

However, bilateral collaboration may not reach equilibrium; collaborative entities may gain different benefits when using the different models. Often, one needs to share the benefits to motivate the others to participate in the collaboration. 


\section{Case Studies}

In this section, we discuss three industrial case studies where the authors have been involved. The first case considers coordinated transportation planning in Sweden involving eight forest companies. The second case was conducted with four North American furniture manufactures aiming for co-distribution to the USA, while the third case is dealing with a bilateral collaboration between a pulp and paper producer and a wholesaler. These cases describe what can be done and raise aspects and considerations when testing and implementing theories in collaborative logistics in practice. They were based on a structured methodology adapted from Lehoux and D'Amours (2004). Table 2 provides a summary of the properties of the three cases.

Table 2. A brief summary of the case studies (LP: Linear Programming, MIP: Mixed Integer Programming)

\begin{tabular}{|c|c|c|c|c|c|c|c|}
\hline Case & $\begin{array}{c}\text { Total } \\
\text { players }\end{array}$ & Industry & $\begin{array}{l}\text { Logistics } \\
\text { approach }\end{array}$ & $\begin{array}{c}\text { Decision } \\
\text { level }\end{array}$ & $\begin{array}{c}\text { OR } \\
\text { method }\end{array}$ & $\begin{array}{c}\text { Stable } \\
\text { equilibrium }\end{array}$ & $\begin{array}{c}\text { Put into } \\
\text { practice? }\end{array}$ \\
\hline 1 & 8 & $\begin{array}{l}\text { Wood } \\
\text { supply }\end{array}$ & 1 & Tactical & LP & $\begin{array}{l}\text { Yes - but not } \\
\text { when imple- } \\
\text { mented }\end{array}$ & $\begin{array}{l}\text { Yes - by } \\
3 \text { players }\end{array}$ \\
\hline 2 & 4 & Furniture & 5 & Operational & Heuristic & $\begin{array}{c}\text { Yes - with cost } \\
\text { allocation }\end{array}$ & Waiting \\
\hline 3 & 2 & Paper & 4 & Operational & MIP & $\begin{array}{l}\text { No- need } \\
\text { incentives }\end{array}$ & Yes - CR \\
\hline
\end{tabular}

\subsection{Wood Supply Collaboration in Sweden}

This first case study is based on work done by the Forest Research Institute of Sweden with eight forest companies involved in transportation of logs from forest harvest areas to industries such as saw, pulp and paper mills (Frisk et al., 2006). Transportation planning is an important part of the supply chain or wood flow chain in forestry. It often amounts to about a third of the raw material cost. There are often several forest companies operating in the same region and coordinated planning between two or more companies is rare. Wood bartering (or timber exchange) between forest companies to reduce transport cost is fairly common in Sweden. In wood bartering, two companies agree to deliver a specific volume to the others company's demand points. The company still plans its operations itself and there is no need to give away any sensitive information. Also, there is no need to provide information about the own savings to the other company.

In 2004 a group of eight forest companies in southern Sweden wanted to know the potential for coordinated transportation planning. Here, all companies viewed their supply and demand as common and a problem for one integrated artificial company could be done. This problem can be solved using the system FlowOpt (Forsberg et al., 2005). The optimization model can be solved with a Linear Programming (LP) model. It turned out that the potential saving was as high as $14.2 \%$. Some part comes from improved planning within each company and the part from collaboration was $8.7 \%$. A very important question is how the savings or the cost should be distributed among the companies. Initially, the companies argued that the total cost should be based on 
their share of the overall volume. However, when we computed the relative savings, it was ranging from $0.2-20 \%$. This difference was too high it was not possible to agree on. The reasons for this difference in relative savings are twofold. First, each company takes responsibility of their own supply and makes sure that it is delivered to the new destinations (coupling between supply and demand points). Secondly, the geographical distribution differs between companies and this affect the new distribution solution.

In order to come up with a sharing principle that the companies could agree on, several sharing principles based on economic models including Shapley value, the nucleolus, separable and non-separable costs, shadow prices and volume weights were tested and analyzed. As a part of the analysis, a new approach, called Equal Profit Method (EPM), was developed. The motivation was to get an allocation that provides an as equal relative profit as possible among the participants. In addition it satisfies core constraints from cooperative game theory and is a stable solution. This approach was acceptable among the forest companies. This was further extended in a two-stage process where the first identified volumes that make a contribution to the collaboration. Then the EPM was applied to these identified volumes.

As a result of the case study, three companies started in 2008 a collaboration where monthly coordinated planning was done. Before each month, each company provided the information about supply and demand to a third party, in this case the Forest Research Institute of Sweden. Then an integrated plan was done and the result was given back to the forest companies for their own detailed transportation planning. The sharing principle was based on having the same relative savings applied to each company own supply. In addition, there were some constraints making sure that each company is the main supplier for its own mills, and that pairwise exchange flows were the same. The latter is to avoid financial exchange between companies. Moreover, some core conditions were not included. With this revised model, it was not possible to guarantee a stable solution. The approach was tested during four months in 2008 and the potential savings were 5-15\% each month.

\subsection{Outbound Transportation Collaboration}

The second case study refers to the potential collaboration between four furniture manufacturers in Canada. The aim was to optimize collectively the outbound transportation of their products to the USA. In Audy and D'Amours (2008), four different logistics scenarios were explored to establish the collaboration. Cost and delivery time reductions as well as gain in market geographic coverage were identified in each scenario. However, even though a scenario can provide substantial benefits for the group, each company needs to evaluate the scenario according to its own benefits. This individual evaluation can lead to a situation where the scenario with the highest cost-savings for the group (optimal cost-savings scenario) does not provide the individual highest cost-savings to some companies or worse, provides one or more negative benefits. As a result, without any modification, this optimal cost-savings scenario would be rejected in favour of another scenario that may not capture all the potential cost-savings and may exclude some of the companies.

Audy et al. (2008) integrated in the optimal cost-savings scenario the modifications which satisfy the conditions allowing its establishment by the whole group. However, 
by doing so, the result in cost reductions go from $21 \%$ to $12.9 \%$. In other words, an additional cost of $8.1 \%$ was incurred in the collaborative plan to satisfy the heterogeneous requirements of some partners. Since some companies have more requirements than others and because the impact on cost increase between two requirements is almost never the same, this raises a new question: how the additional cost incurred to satisfy the special requirements should be shared between the companies? Using the solution concept of a cost allocation scheme called Alternative cost avoided method (see Tijs and Driessen, 1986), a new method was proposed and analyzed. This new method allows a share according to the impact of the requirements of each partner on the cost of the collaborative plan. Thus, the partner who increases the most the cost of the collaborative plan obtains the highest part of the additional cost incurred to satisfy the requirements of all partners. The previous costs allocated to each partner were then considered as a fix cost parameter in a sharing principle to determine the individual cost-savings of each company. The Equal Profit Method proposed by Frisk et al. (2006) was used as the sharing principle with two modifications: (i) to tackle the previous fix cost parameter and also two other fix cost parameters typical to the furniture industry, and (ii) to ensure a minimum cost-savings percentage for each partner.

As a result of the case study, a pilot project was initiated by companies with the support of their industrial association. As agreed by the four companies, one of them defined a business agreement to manage the collaboration in the pilot project. The definition of the business agreement was delayed for many reasons and then, one opportunistic company used the transportation rates inside the business agreement to put pressure on its carriers to reduce its own transportation rates. Since that, the project pilot was suspended but was not abandoned by the three other companies.

\subsection{Collaboration Approaches in the Pulp and Paper Industry}

The last case concerns a pulp and paper producer who decided to establish a partnership with one of its clients (Lehoux et al., 2008). Since the production capacity was limited, the producer had to plan operations in order to satisfy the demand of the partner and the demand of other clients. The partner was a wholesaler, thus he bought products and sold them to consumers without transforming the merchandise. Even if each partner wanted to create a real partnership with mutual benefits, they made decisions based on their local costs rather than the global costs of the system. The producer planned operations in order to minimize production, distribution and inventory costs, while the wholesaler ordered products so as to minimize buying, ordering and inventory costs. For this context, the idea was to identify the collaboration model to use to ensure an efficient exchange of products and information as well as maximum benefits for the network and for each partner. Four potential approaches were first identified for the case study: a traditional system without any collaboration scheme, CR, VMI and CPFR. For each approach, decision models from the point of view of both the producer and the wholesaler were developed. Specifically, Mixed-Integer Linear Programs (MIP) were used to take into consideration the costs, revenues and constraints involved in using each approach. Afterwards, models were tested and compared so as to find the type of relationship the most profitable for the system. Results showed that CPFR generates the greatest total system profit because of an efficient optimization of both transportation and inventory costs (CPFR inventory cost 
up to $44 \%$ lower than inventory costs of other approaches). VMI is second best since the transportation cost is optimized. CR and the traditional system obtain the lowest total system profit.

After comparing each model using the system profit, the investigation was based on the profit of each partner. Specifically, the different types of relationship were compared to verify if the same approach could generate the highest profit for both the producer and the wholesaler. This analysis revealed that CPFR generates the greatest profit for the producer, while the CR technique is the most beneficial for the wholesaler. For this reason, a method for sharing benefits was defined so as to obtain a CPFR collaboration profitable for each partner. Results showed that if the producer shares a part of the transportation savings with the wholesaler, the profit of the wholesaler is higher than the profit obtained with CR, and the producer obtains a higher profit than the one generated by other approaches.

Actually, partners work together using a CR technique. But in the future, they aim to implement a form of CPFR. Therefore, as observed in the study, they will certainly have to share benefits if they want to establish a win-win relationship. Otherwise, it is possible that the wholesaler may prefer to work with someone else.

\section{Concluding Remarks}

This paper sought to review some critical issues in building and planning a coalition with the aim of conducting collaborative logistics. As shown throughout the paper, the interest for this domain is rising in the academic community as well as in industry.

Even though new ideas and methods are provided to support the different decisions, many problems are still very difficult to deal with. These problems often call for interdisciplinary solutions and collaborative network is emerging as a new discipline to study such collaborative issues (Camarinha-Matos and Afsarmanesh, 2005). For example, in the process of building a coalition, some entities may be strong competitors. In such a case, trust may play an important role in the decision process. Moreover, building a coalition involves taking into consideration implementation costs, risk, information needs, the share of costs/benefits and all the difficulties that could emerged from the collaboration.

Each of the cases discussed brings up interesting issues. The first case has identified different strategies for costs sharing. The need for a fair approach clearly illustrates the values of the companies involved. The second case raises issues in dealing with non tangible benefits as well as specific requirements and their impact on the collaborative cost structure. Finally, the third case describes a context where the only way to obtain a stable equilibrium is through the share of savings.

The case studies express a variety of strategies. However, all were studied on the basis of post-information. Great challenges still remain to support the day-to-day operations of such coalition, managing efficiently variations such as market changes or currency fluctuations. The changing context in which a coalition evolves may require a revision of the collaboration policies. When implementing theoretical models in practical collaborative logistics, it is also important to match these theories with practical issues and the planners' understanding, goals and restrictions. 


\section{References}

1. Audy, J.-F., D'Amours, S.: Impact of benefit sharing among companies in the implantation of a collaborative transportation system - An application in the furniture industry. In: Camarinha-Matos, L., Picard, W. (eds.) IFIP International Federation for Information Processing, Springer, Heidelberg (2008)

2. Audy, J.-F., D'Amours, S., Rousseau, L.-M.: Cost allocation in the establishment of a collaborative transportation agreement-an application in the furniture industry. Working paper, CIRRELT, CIRRELT-2008-50 (2008)

3. Beaudoin, D., LeBel, L., Frayret, J.-M.: Tactical supply chain planning in the forest products industry through optimization and scenario-based analysis. Can. J. For. Res. 37(1), 128-140 (2007)

4. Camarinha-Matos, L.M., Afsarmanesh, H.: Collaborative networks: A new scientific discipline. J. Intellig. Manuf. 16(4-5), 439-452 (2005)

5. Cederlund, J.P., Kohli, R., Sherer, S.A., Yao, Y.: How Motorola put CPFR into action. Supply Chain Management Review, 28-35 (October 2007)

6. D'Amours, F., D'Amours, S., Frayret, J.-M.: Collaboration et outils collaboratifs pour la PME Manufacturière. Technical report, CEFRIO (2004)

7. Danese, P.: The extended VMI for coordinating the whole supply network. J. Manuf. Techn. Manag. 17(7), 888-907 (2006)

8. Eriksson, J., Rönnqvist, M.: Decision support system/tools: Transportation and route planning: Åkarweb - a web based planning system. In: Proceedings of the 2nd Forest Engineering Conference, Växjö, Sweden, May 12-15 (2003)

9. Frayret, J.-M., D’Amours, S., Montreuil, B.: Co-ordination and control in distributed and agent-based manufacturing systems. Prod. Plann. and Cont. 15(1), 1-13 (2004)

10. Forsberg, M., Frisk, M., Rönnqvist, M.: FlowOpt - a decision support tool for strategic and tactical transportation planning in forestry. Int. J. For. Eng. 16(2), 101-114 (2005)

11. Frisk, M., Jörnsten, K., Göthe-Lundgren, M., Rönnqvist, M.: Cost allocation in collaborative forest transportation. Working paper (2006) (to appear in EJOR)

12. Montreuil, B., Frayret, J.-M., D'Amours, S.: A Strategic Framework for Networked Manufacturing. Compt. in Indust. 42(2-3), 299-317 (1999)

13. Moyaux, T., Chaib-draa, B., D'Amours, S.: The impact of information sharing on the efficiency of an ordering approach in reducing the bullwhip effect. IEEE Trans. Syst. Man. \& Cyb. (Part C) 37(3) (2007)

14. Lee, H.L., Padmanabhan, V., Whang, S.: Information Distortion in Supply Chain: the Bullwhip Effect. Manag. Science 43(4), 546-558 (1997)

15. Lehoux, N., D'Amours, S., Langevin, A.: Collaboration and decision models for a two-echelon supply chain: a case study in the pulp and paper industry. Working paper, CIRRELT, CIRRELT-2008-29 (2008) (to appear in JOL)

16. Lehoux, N., D'Amours, S.: La collaboration interentreprises dans le secteur alimentaire: l'Étude d'une relation entre manufacturier et distributeur. R. Franç. Gest. Indust. 23(2) (2004)

17. Tijs, S.H., Driessen, T.S.H.: Game theory and cost allocation problems. Manag. Science 32(8), 1015-1028 (1986) 